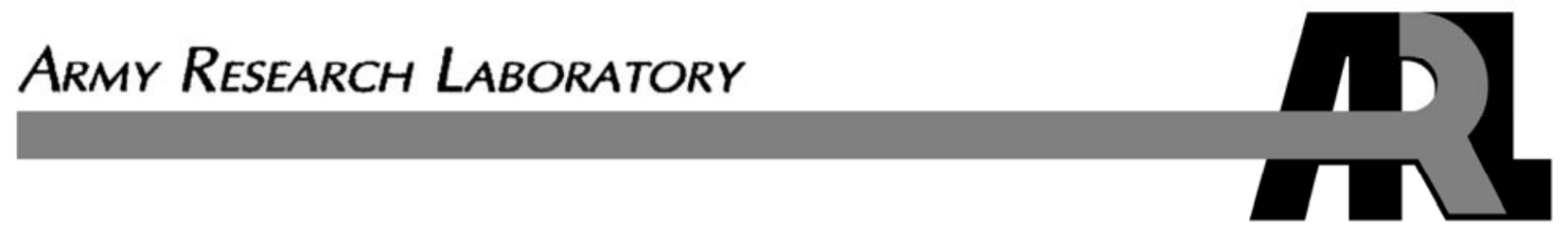

\title{
Instrumentation and Tactor Considerations for a Head-Mounted Tactile Display
}

\author{
by Joel T. Kalb, Bruce E. Amrein, and Kimberly Myles
}




\section{NOTICES}

\section{Disclaimers}

The findings in this report are not to be construed as an official Department of the Army position unless so designated by other authorized documents.

Citation of manufacturer's or trade names does not constitute an official endorsement or approval of the use thereof.

Destroy this report when it is no longer needed. Do not return it to the originator. 


\section{Army Research Laboratory}

Aberdeen Proving Ground, MD 21005-5425

\section{Instrumentation and Tactor Considerations for a Head-Mounted Tactile Display}

Joel T. Kalb, Bruce E. Amrein, and Kimberly Myles

Human Research \& Engineering Directorate, ARL 


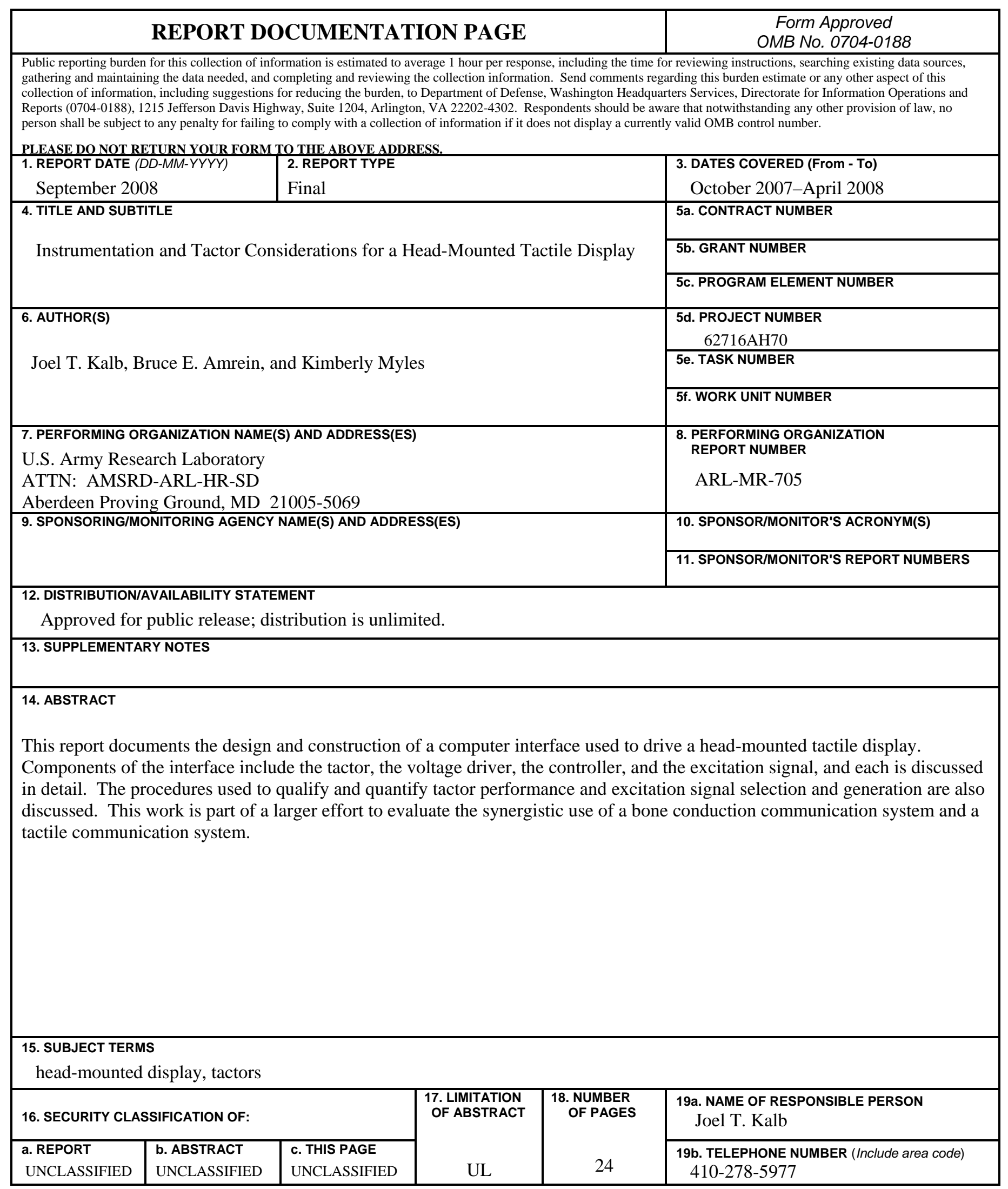




\section{Contents}

List of Figures $\quad$ iv

1. Introduction $\quad 1$

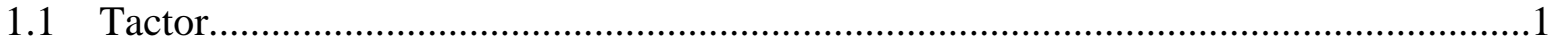

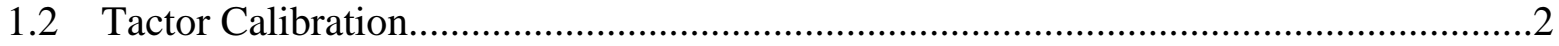

2. Equipment $\quad 4$

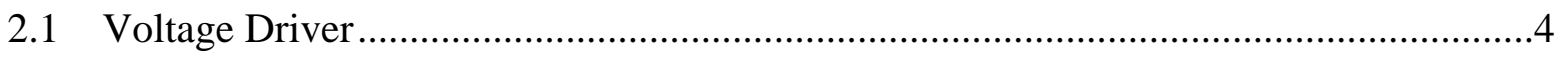

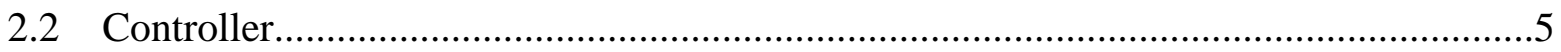

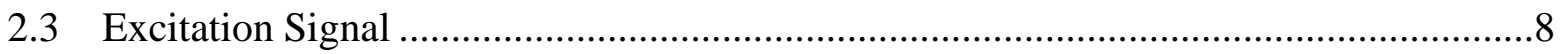

3. Methodology: Translating Obtained Threshold Voltages for Skin Excitation to Displacement

3.1 The Translation of Obtained Threshold Voltages to Displacement With the Fingertip

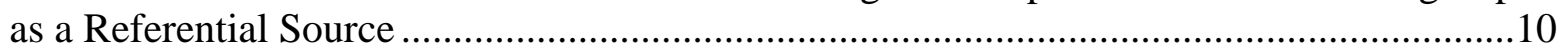

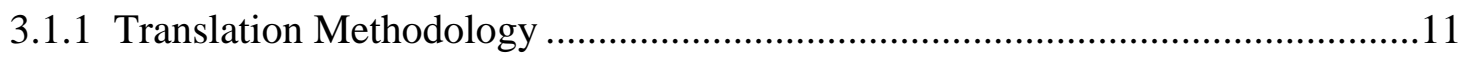

$\begin{array}{lr}\text { 4. Conclusions } & 14\end{array}$

5. References $\quad 15$

$\begin{array}{ll}\text { Distribution List } & 16\end{array}$ 


\section{List of Figures}

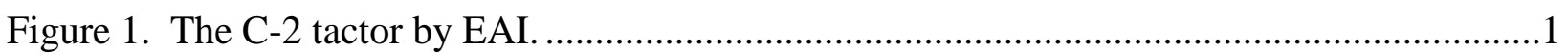

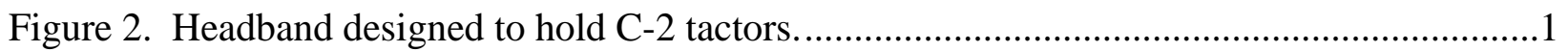

Figure 3. The tactor geometry with a moving contactor and surrounding housing........................2

Figure 4. Equipment used to measure displacement vs. direct current...............................................

Figure 5. Comparison of displacement vs. current of ten C-2 tactors. (Note: The data gathered in this test should not be used as absolute data to specify displacement vs. AC or DC signals applied when the tactor is operating in free space or when applied to skin.)...........3

Figure 6. Stimulation path through the tactor and skin.................................................................

Figure 7. Schematic diagram of boosted operational amplifier suitable for driving C-2 tactors.

Figure 8. Schematic of multiplexed tactor driver for parallel printer port and headphone audio output jack on a notebook computer. (Three boosted operational amplifiers [AMP0, AMP1, AMP7] and tactors are shown connected at the output connector J4. Additional switches are connected to connector J2 to support detection and localization experiments: the two hand switches, S1 and S2 allow 2AFC [two alternate forced choice] decisions to be made in time or in location. For more detailed localization choices, an external keypad is connected to a USB port on the computer. At the bottom of the diagram, the logic level converter symbol is shown next to the circuit used to convert transistor-transistor logic [TTL] to complementary symmetry metal oxide semiconductor [CMOS] logic levels.)

Figure 9. The first cycle of the waveform with a period of $250 \mathrm{~ms}$ and duty cycle fraction of 0.25 . (The carrier frequency is $144 \mathrm{~Hz}$, which gives nine complete cycles over the "on" time of the modulation: three cycles for each of the three on phases: rising, sustain, and falling. Note: Two pulses fit in the 300-ms time interval assumed to be the time constant for temporal summation in the skin receptors.)

Figure 10. Vibration threshold for sinusoidal pulses for the finger with and without a rigid surround. (The curve through the data points for the five observers was fitted by eye. The standard deviation was $5 \mathrm{~dB}$. The contactor area was $1.5 \mathrm{~cm}^{2}$ and the static force was $0.5 \mathrm{~N}$ [data from Lamoré and Keemink, 1988].).

Figure 11. Tactor voltage threshold for sinusoidal pulses for the finger with a rigid surround (for four pilot participants). (The contactor area was $0.46 \mathrm{~cm}^{2}$ and the static force was 0.17 N.)

Figure 12. Tactor voltage threshold for sinusoidal pulses for the finger with a rigid surround. (The contactor area was $0.46 \mathrm{~cm}^{2}$ and the static force was $0.17 \mathrm{~N}$.)

Figure 13. Tactor voltage threshold for sinusoidal pulses for the finger with a rigid surround. (The contactor area was $0.46 \mathrm{~cm}^{2}$ and the static force was $0.17 \mathrm{~N}$. Second order low-pass maximally flat Butterworth mechanical filter response with a 250-Hz cutoff frequency, $\mathrm{Q}=0.707$ and low-frequency gain $=11.5 \mathrm{~dB}$.) 


\section{Introduction}

This report documents the design and construction of a computer interface used to drive a headmounted tactile display. The components of the computer interface include the tactor, the voltage driver, the controller, and the excitation signal.

\subsection{Tactor}

The tactor used for the design of the head-mounted tactile display is the C-2 tactor by Engineering Acoustics, Inc. (EAI) (www.eaiinfo.com) (see figure 1). The headband designed to hold seven C-2 tactors in place on the head is shown in figure 2.

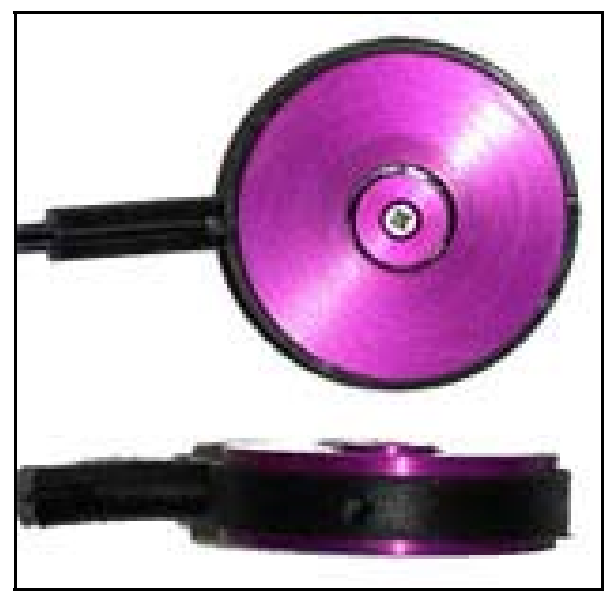

Figure 1. The C-2 tactor by EAI.

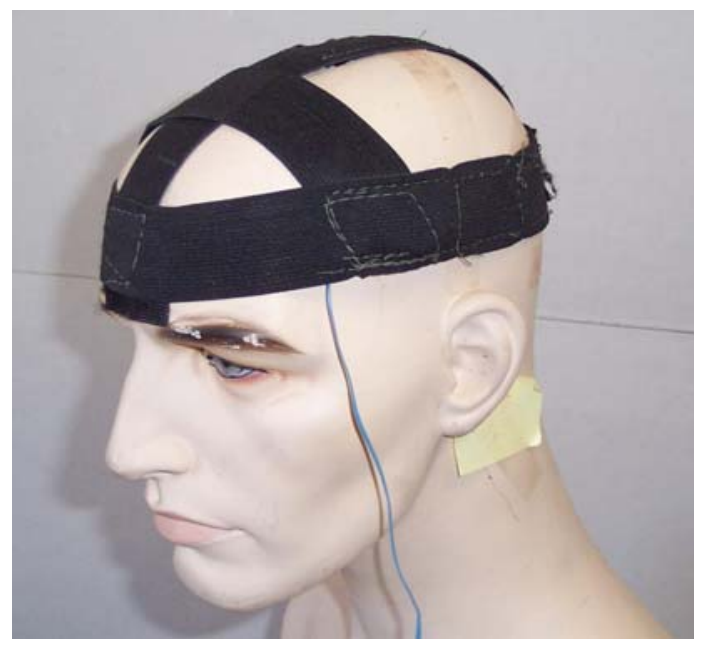

Figure 2. Headband designed to hold C-2 tactors. 
Figure 3 shows a geometric drawing of the wearable vibro-tactile tactor which is suitable for stimulating smooth (glabrous) or hairy skin. It consists of an electro-magnetically driven moving (skin) contactor surrounded by an air gap and a rigid housing called a "surround." The contactor surface area is $0.38 \mathrm{~cm}^{2}$ and is offset $0.64 \mathrm{~mm}$ above the housing (with an area of $6.4 \mathrm{~cm}^{2}$ ) and radially separated from it by a 1-mm gap. The two elements exert equal opposing forces on the skin with vibrations generated by the contactor being damped by the surround, giving a localized sensation.

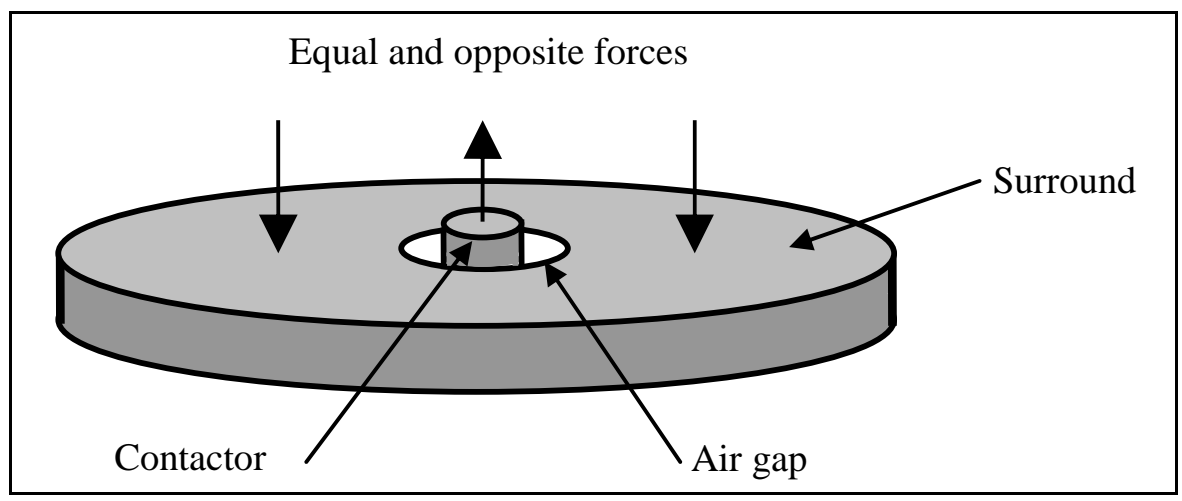

Figure 3. The tactor geometry with a moving contactor and surrounding housing.

\subsection{Tactor Calibration}

Ten tactors were obtained from EAI, and measurements were taken to confirm that each was capable of producing similar tactile output (within acceptable limits of variability according to tactor specifications). The intent of the calibration procedure was to verify that tactors operated in accordance with published specifications and to identify any tactors that should not be used for further experimentation because of their non-compliance with the published specifications.

Displacement vs. direct current was measured for each tactor with a 0.0001-in dial indicator, power supply, and milliampere ( $\mathrm{mA}$ ) meter, as shown in the photographs in figure 4 . The tactors were polarized so that a positive voltage applied to the center pin of the attached RCA* connector caused a positive displacement of the skin contactor in an outward direction from the surround. Skin contactor pre-load was physically measured for each tactor. (Note: Tactor 2 demonstrated an abnormal pre-load of 0.010 in, significantly less than the EAI-specified pre-load of 0.025 in.) Direct current (DC) resistance was measured for each tactor and was found to be between 6.2 and 6.3 ohms $(\Omega)$. (Note: The specifications show a typical impedance of $7 \Omega$.)

The contactor displacement is very sensitive to skin loading (Mortimer et al., 2007); therefore, we performed comparisons by gently placing the contact point of the dial indicator on the skin contactor, setting the dial indicator to zero with zero current flow, and then increasing the current in 50-mA increments. After the current was recorded, we recorded displacement of the contactor with respect to the surround by sliding a tactor under the contact point of the dial

\footnotetext{
* Radio Corporation of America.
} 


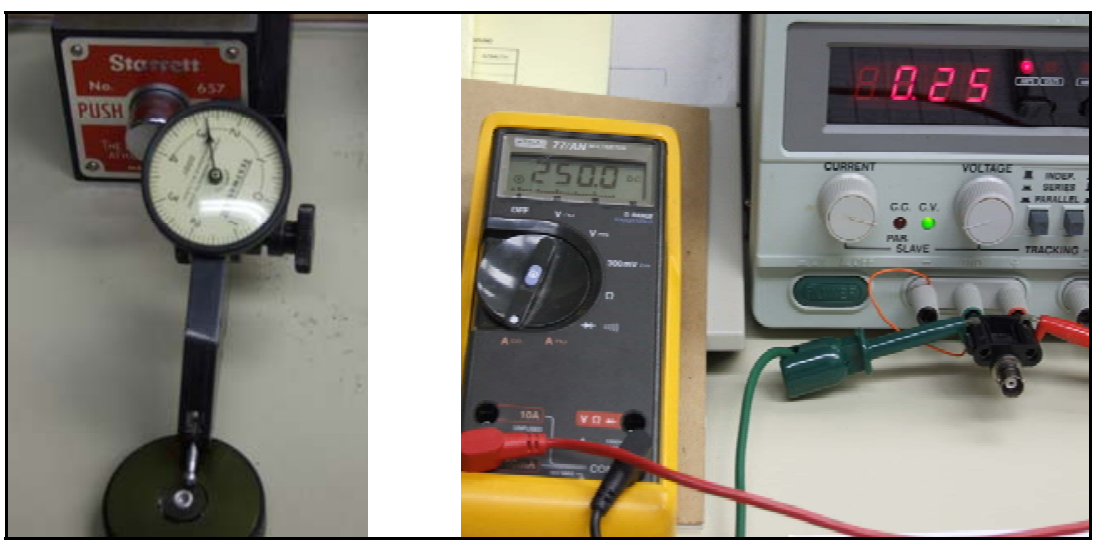

Figure 4. Equipment used to measure displacement vs. direct current.

indicator several times until a repeatable displacement reading was obtained. The range of displacements recorded at the same current for the same tactor sometimes varied by several tenthousandths of an inch, but this was not unexpected because of the mechanical measurement configuration. This measurement procedure was repeated at 50-mA increments until $300 \mathrm{~mA}$ (which is $50 \mathrm{~mA}$ over the recommended short duration drive current). After data were collected at each value of current, the excitation voltage was removed (returning the tactor to a zero current condition), and the zero reading was recorded with the dial indicator to verify that a zero shift had not occurred. Two tactors experienced minor zero shifts. The measurement procedure was repeated without re-zeroing. In conclusion, nine of the ten tactors (all but tactor 2, which exhibited abnormal pre-load) are suitable for use in the head-mounted tactile display, and with DC excitation voltage, the tactors appear to perform in a similar fashion (see figure 5).

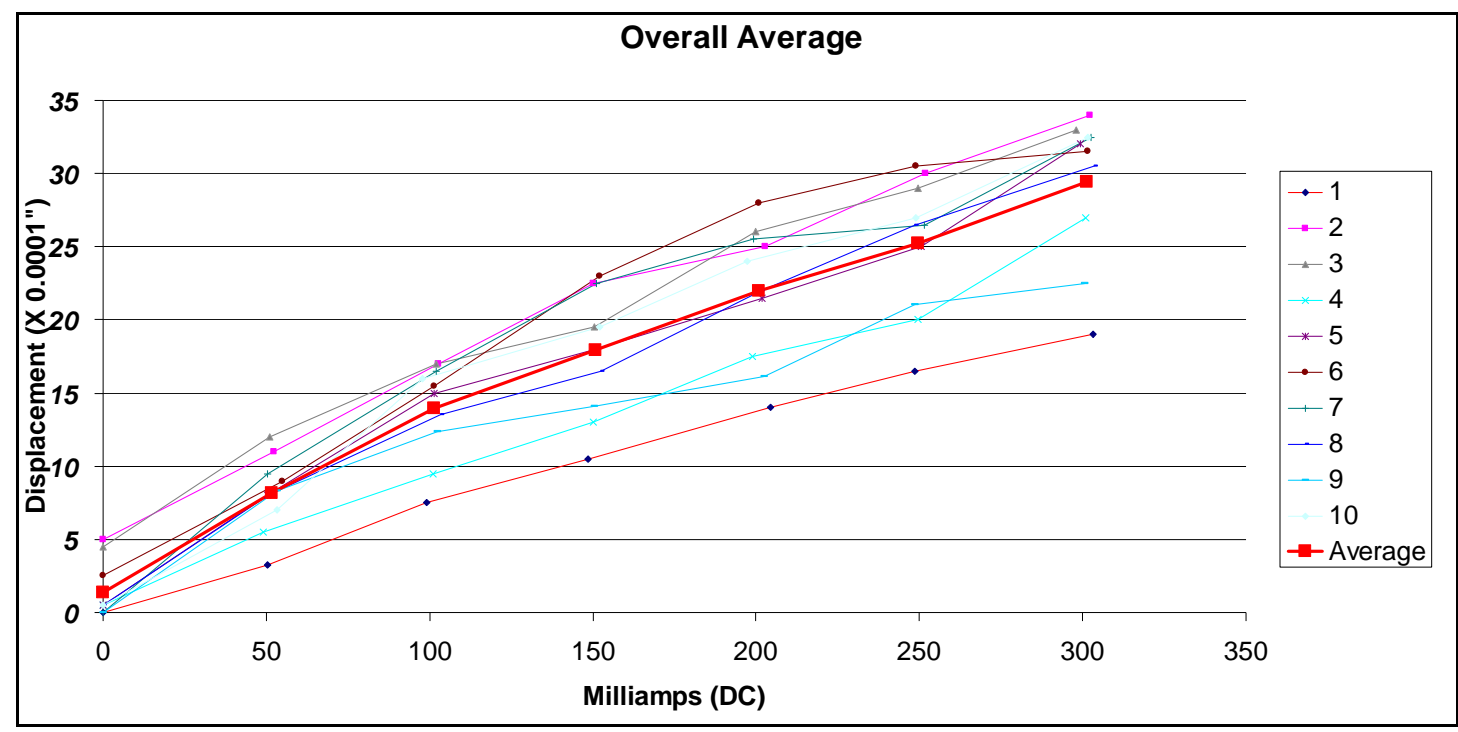

Figure 5. Comparison of displacement vs. current of ten C-2 tactors. (Note: The data gathered in this test should not be used as absolute data to specify displacement vs. AC or DC signals applied when the tactor is operating in free space or when applied to skin.) 


\section{Equipment}

\subsection{Voltage Driver}

In figure 6 , the voltage driver amplifies the signal, $\mathrm{G}$, thus producing a voltage, $\mathrm{V}$, with low $(<0.01 \Omega)$ output impedance because of the two emitter-follower output transistors and negative feedback. This voltage is maintained because the amplifier is not loaded by the tactor impedance which is typically $7 \Omega$ but increases with frequency because of a reactive component caused by the coil inductance and contactor mass.

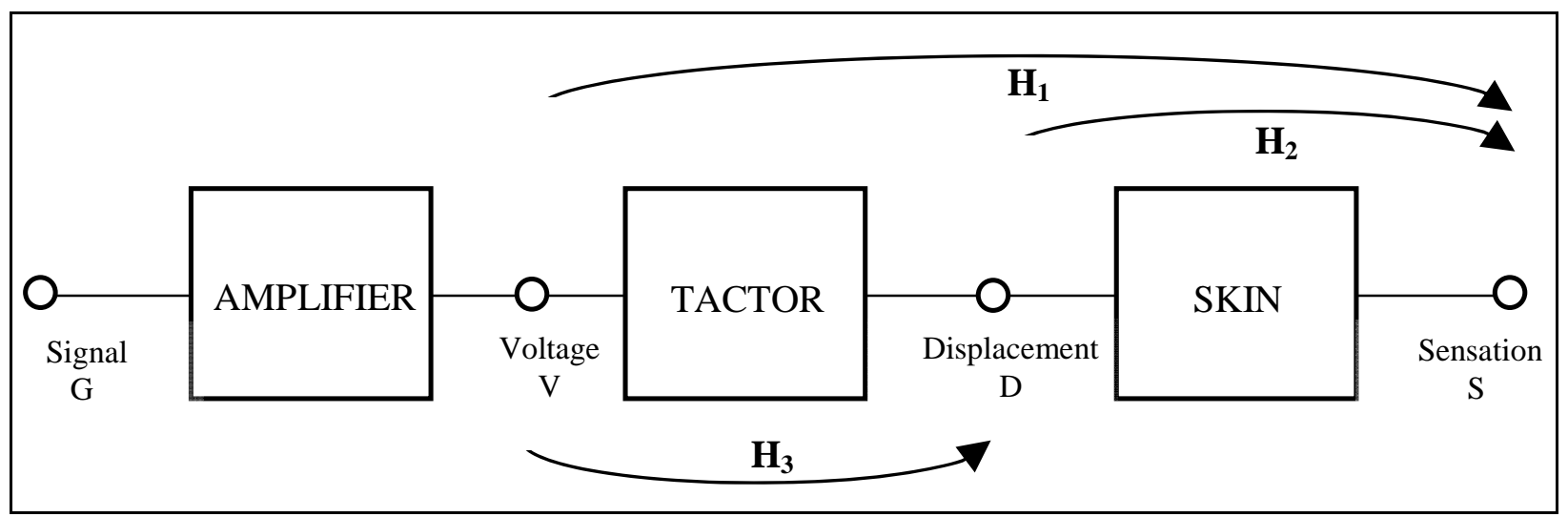

Figure 6. Stimulation path through the tactor and skin.

The C-2 tactor electrical input impedance is typically $7 \Omega$ and the recommended driver should be able to supply at least 0.5 ampere root mean square (rms) for short durations. This requires 1.75 watts (W) and 3.5 volts (V) rms which exceeds the capability of common audio equipment such as note-book computers $(0.085 \mathrm{~W}$ and $1 \mathrm{~V} \mathrm{rms})$. Another problem with such consumer audio equipment is the low frequency cut-off point of $20 \mathrm{~Hz}$, which reduces damage to loudspeakers and headphones. In this case, the use of common audio equipment also restricts the useful low frequency range of the tactor. Note that some headphone drivers on notebook computers do not have this limit and are advertised as having higher fidelity (probably for better response in newer sub-woofer home theater systems). In the driving of the tactor, it is important not to create higher frequency artifacts from peak-clipping distortion, which may be readily detected by the ear, in addition to being detected by touch. We therefore initially used a Tucker Davis Technologies (TDT) (www.tdt.com/) System 2 array processor (TDT-2AP) along with a boosted operational amplifier (op-amp) shown in figure 7. 


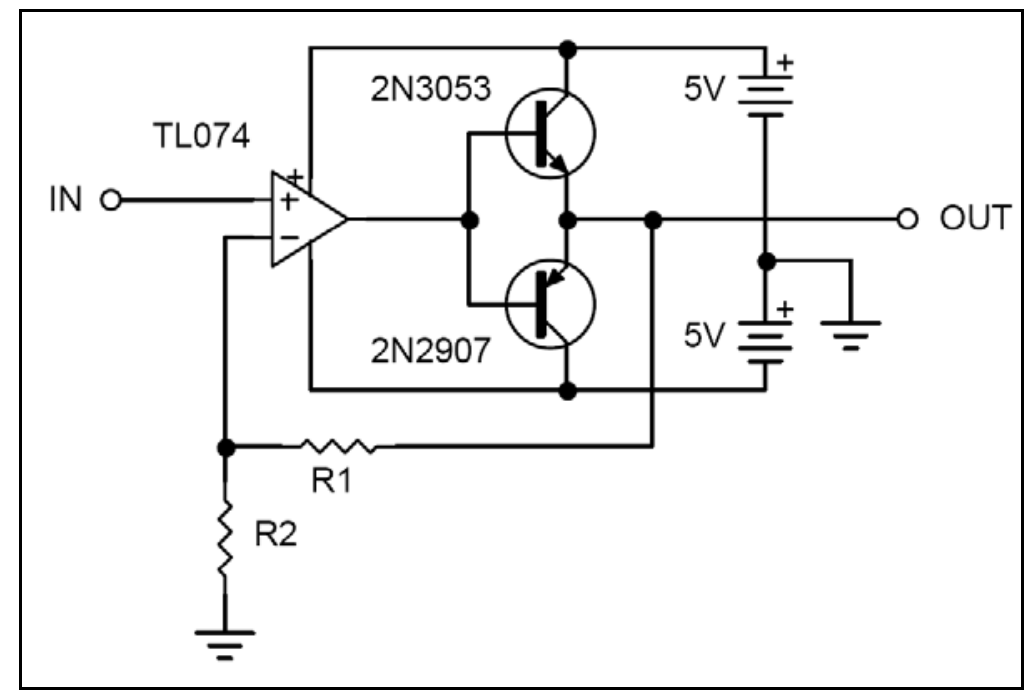

Figure 7. Schematic diagram of boosted operational amplifier suitable for driving C-2 tactors.

The TDT system was used primarily because it provided a wide range of signal levels $( \pm 10-\mathrm{V}$ peak) and frequencies (0 to $100 \mathrm{kHz}$ ) with eight independent audio output devices (DAC3-8 module). The TL074 op-amp maintains this frequency range for the required voltages and is boosted in current capability from its normal $10 \mathrm{~mA}$ by the current gain of the two bipolar power transistors, which is typically 100 . Voltage gain is provided by the negative feedback path resistors R1 and R2 (gain = $1+\mathrm{R} 1 / \mathrm{R} 2$ ). (Note: Unity gain is given by $\mathrm{R} 1=0$ and a gain of 2 occurs for R1 = R2 = $10 \mathrm{k} \Omega$ typically.) The transistors and negative feedback also give nearly zero output impedance which improves the tactor output fidelity. The ability of the transistors and op-amp to remain active imposes a limit of $\pm 2.25 \mathrm{~V}$ peak when used with the 5 - $\mathrm{V}$ power supplies (figure 7), however. (Note that higher power supply voltages can be used with a resulting heat dissipation increase.) Another advantage of using the TL074 op-amp is that it provides four amplifiers in a single 16-pin package and they do not require any external compensation for stability.

\subsection{Controller}

The TDT system is an ISA (industry standard architecture) bus device that limits its use to older PCs that are no longer readily available. In order to make a multiplexed tactor device (as opposed to the 12-channel tactor driver/interface/controller available from EAI), we designed a device that could be controlled by the parallel printer port and headphone audio output devices which are readily available on notebook computers. We try to avoid the problem of low frequency cut-off at $20 \mathrm{~Hz}$ by selecting a high-quality notebook computer. The circuit diagram is shown in figure 8 . 


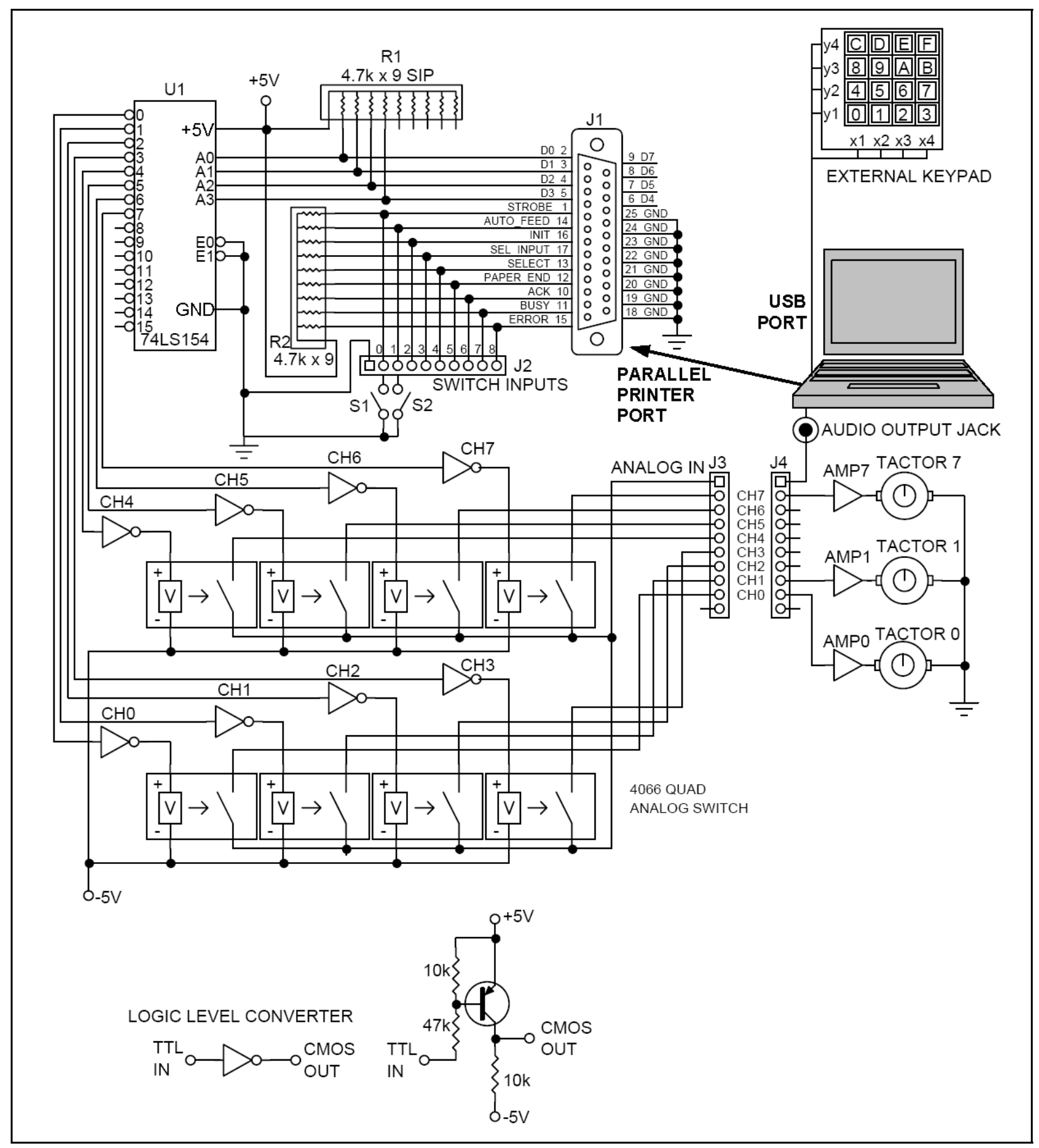

Figure 8. Schematic of multiplexed tactor driver for parallel printer port and headphone audio output jack on a notebook computer. (Three boosted operational amplifiers [AMP0, AMP1, AMP7] and tactors are shown connected at the output connector J4. Additional switches are connected to connector J2 to support detection and localization experiments: the two hand switches, S1 and S2 allow 2AFC [two alternate forced choice] decisions to be made in time or in location. For more detailed localization choices, an external keypad is connected to a USB port on the computer. At the bottom of the diagram, the logic level converter symbol is shown next to the circuit used to convert transistor-transistor logic [TTL] to complementary symmetry metal oxide semiconductor [CMOS] logic levels.) 
Figure 8 shows the eight binary input and output devices available at the commonly available parallel printer port which is configured for bi-directional operation. This circuit was motivated by numerous examples of practical interface designs described in Bergsman (1994). A problem with recent notebook computers is the lack the parallel printer port which is replaced by multiple universal serial bus (USB) ports in support for newer printers. One solution is to use a USB to DB25 Institute of Electrical and Electronics Engineers-1284 printer adapter cable

(www.CablesTo Go.com), which is fully transparent to bi-directional communication application programs.

The port levels are compatible with the TTL family of integrated circuits ( 0 to $3.5 \mathrm{~V}$ ) while the analog switches are implemented in the 4000 family of CMOS configured to operate between $\pm 5 \mathrm{~V}$ in order to pass the audio signals which range between $\pm 2.25 \mathrm{~V}$. The logic levels are converted by the common emitter transistor at the bottom of figure 8 along with its equivalent inverter circuit symbol. This operates when the input TTL level goes low, drawing current through the two bias resistors that turn on the transistor, pulling its collector up from $-5 \mathrm{~V}$ to $+5 \mathrm{~V}$. This, connected to the voltage control of the following 4066 analog switch, causes the analog channel to conduct. The common analog input (coming from the line output of the notebook computer) is routed to the selected voltage driver and tactor. The logic inverters are driven by eight output devices of the one-of-16 decoder 74LS154 which in turn is driven by four output data lines D0-D3 of the parallel printer port at the standard IBM (International Business Machines) PC printer port DB-25 (25 pin) on all desktop and some notebook computers. For data collection, provision is made for as many as eight hand switches that signal the participant's responses back to the computer through the parallel port (figure 8) or with a hex keypad through the newer USB port. These pins are compatible with commonly available TTL integrated circuits. Source code in three common programming languages (C, Pascal, and Visual Basic) read and write these pins. The port is addressable as LPT1 $=0 \times 0408$, LPT2 $=0 \times 040 \mathrm{~A}$, or LPT3 $=040 \mathrm{C}$. The available printer ports are found by PEEK $(0,0 \times 400+6+($ Lpt_NUM*2)) looking for a non-zero response. The selected printer port is initialized with read only memory-basic input/output system (BIOS) service routine $\$ 17$, function $\$ 01$. The following $\mathrm{C}$ code describes how the parallel port can be programmed (Bergsman, 1994).

// HEX BASE ADDRESS Port $\mathrm{A}=0 \times 3 \mathrm{BC}$, Port $\mathrm{B}=0 \times 378$, Port $\mathrm{C}=0 \times 278$

// check that selected printer port is actual installed on machine

// return port address from BIOS variable segment, (Lpt_Port_Address (p244)

// Every computer language contains specific commands to "talk" to the LPT1 printer (for example, Pascal uses LST while BASIC uses LPRINT. If your application just outputs data, then this technique can simplify your code. (p. 237 )

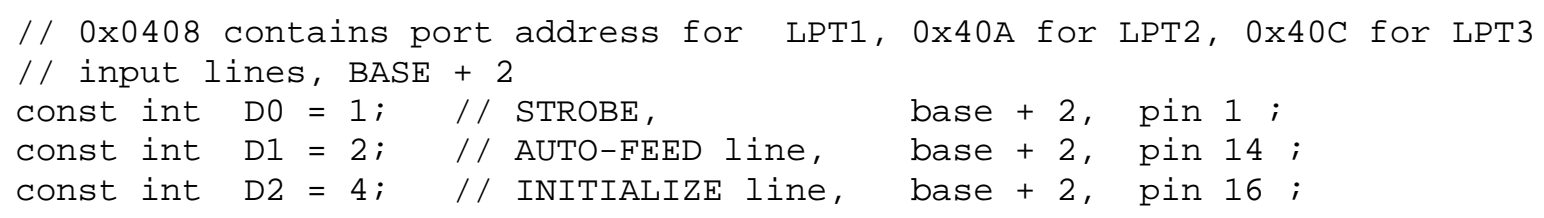




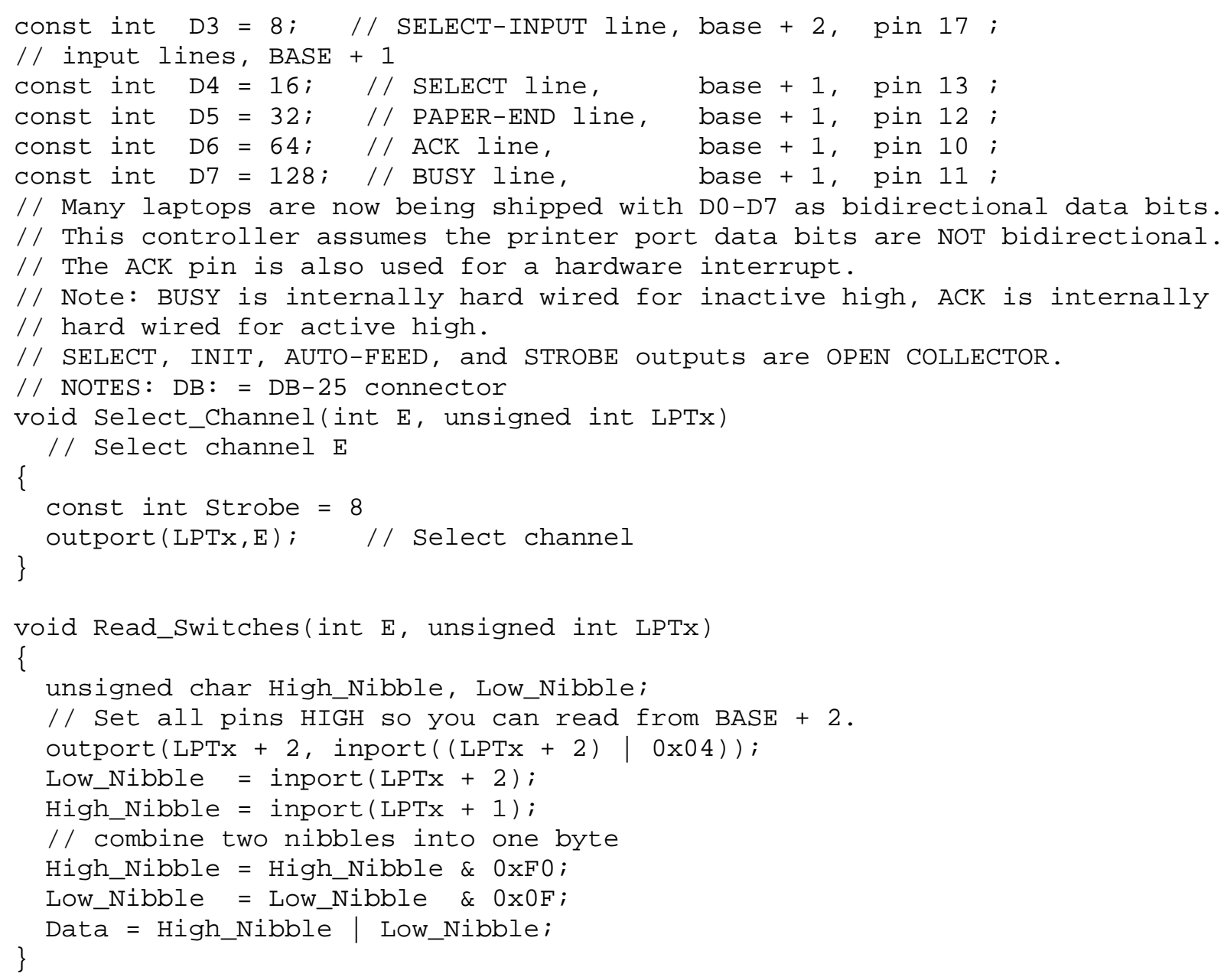

\subsection{Excitation Signal}

A modulated sinusoidal carrier wave was chosen as the stimulus motivated by the general principle that stimulation of the senses is a two-part process. First, the carrier wave with a given frequency $f_{\mathrm{c}}$ "carries" the signal from the source through the medium to the sensitive nerve ending, but no information or meaning is transported by itself. The purpose of the modulation is to convey the message of the signal. In this case, it is a series of pulses with $\mathrm{T}$ being the cycle period, $\delta$ equal to the duty cycle on fraction. Furthermore, during the "on" time, the pulse is divided into three parts, each of duration $\tau=1 / 3 \delta T$. During the first phase, the signal envelope rises to full strength, where it remains during the sustaining second phase, and then during the third phase, it falls back to zero and remains there during the "off” time of the duty cycle. The rise and fall transitions follow a half-cosine pattern. The whole cycle is repeated a number of repetitions, $\mathrm{N}_{\text {rep. }}$. The combined carrier and modulation is then

$$
g(t)=f(t) \cdot \cos \left(2 \pi f_{c} \mathrm{t}\right),
$$

where the modulation function is 


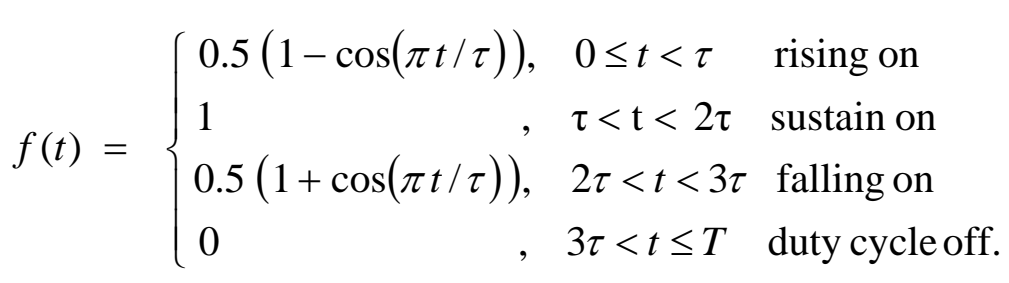

The carrier frequencies were chosen from standard one-third octave band center values given by $f_{c}=10^{N / 3}$, in which $\mathrm{N}$ is the band number from 3 to 30 . The cycle period was $250 \mathrm{~ms}$, the duty cycle fraction $\delta$ was 0.25 , and the number of repetitions was three, so the whole stimulation lasted $750 \mathrm{~ms}$. The signal amplitude at the tactor was $2.25 \mathrm{~V}$ (0 to peak). The repetition rate was chosen so that two successive pulses fit within the 300-ms integration time needed to fully stimulate the touch sensation (Verrillo, 1965). If the signal does not substantially fill this interval, then the sensation begins to decline at the rate of $3 \mathrm{~dB}$ per halving of duration. The gradual signal change during the rising and falling phases prevents upward frequency spread, possibly detectable by senses other than tactile such as hearing from bone or air conduction (figure 9).

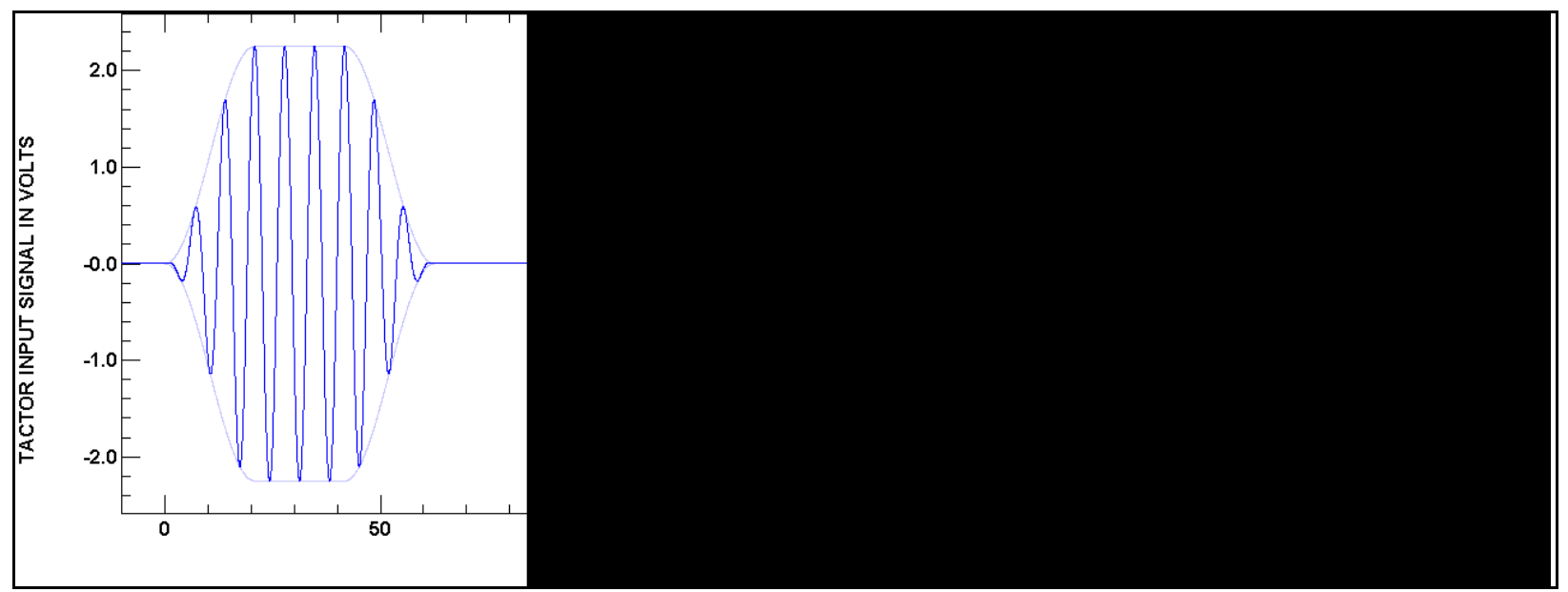

Figure 9. The first cycle of the waveform with a period of $250 \mathrm{~ms}$ and duty cycle fraction of 0.25 . (The carrier frequency is $144 \mathrm{~Hz}$, which gives nine complete cycles over the "on" time of the modulation: three cycles for each of the three on phases: rising, sustain, and falling. Note: Two pulses fit in the 300-ms time interval assumed to be the time constant for temporal summation in the skin receptors.)

\section{Methodology: Translating Obtained Threshold Voltages for Skin Excitation to Displacement}

The model shown in figure 6 also displays the signal flow from the signal source to the skin sensation as a function of the transfer functions of the three blocks and the input and output impedances at each connecting point. The transfer at each block depends not only on its gain but 
also on how its driving output impedance is loaded by the input impedance of the next stage. The blocks should not be considered isolated from the respective loads.

Vibration detection is enhanced by skin indentation at the contactor (figure 3) and neural contrast processes (as high as $20 \mathrm{~dB}$ in the low frequency region from 5 to $50 \mathrm{~Hz}$ ). The skin then loads the contactor with additional mass and damping, thereby lowering its resonant frequency and displacement response to a given excitation voltage. Careful design minimizes these effects and at the same time optimizes the efficiency of the stimulation for limited power and weight.

The interaction between the tactor and skin makes it difficult to directly measure the tactor displacement response; the manufacturer of the tactor used a skin simulator made from two gel layers covered with a latex-rubber membrane along with a fiber-optic displacement sensor (Mortimer et al., 2007). Their measurements were combined with a mechanical impedance model of the tactor plus skin as part of the design optimization. Our indirect method of measuring tactor displacement response is summarized next.

\subsection{The Translation of Obtained Threshold Voltages to Displacement With the Fingertip as a Referential Source}

An indirect calibration procedure was created to convert future obtained threshold voltages for tactile perception on the head at selected frequencies to displacement. We used the extensive measurements available for the finger which has concentrated receptors for use in determining textures and in feedback for manipulation.

Specifically, we associated our threshold measurements from the fingertip via stimulus voltages with Lamoŕe and Keemink (1988) displacement measurements using the fingertip. The equal detection vibration amplitude transfer function was then applied in reverse to determine the effective displacement at each excitation voltage at the tactor. This then gives a calibration between applied voltage and effective displacement expressed as displacement in decibels referred to a reference of $1 \mu \mathrm{m} 0$ to peak.

Considering this unit, Verrillo (1962) discusses vibration control and ways of measuring the stimulus at the site of excitation chosen to be the displacement amplitude in microns $\left(1 \mu=10^{-6} \mathrm{~m}\right)$. These values were converted to decibels referred to a displacement of $1 \mu \mathrm{m}$ to indicate the logarithmic behavior in general of sensation with stimulus. Later, Verrillo (1985) changed the measured displacements and reference quantity (1.0- $\mu \mathrm{m}$ peak) in terms of peaks emphasizing that quantity over root mean square in a comparison of modulated sinusoids and random noise for example (where the latter is more suited in comparing stimuli with equal energy).

Assuming that the load impedance and static forces do not change between the finger and the head, this also provides threshold measurements on the head in terms of effective displacement of the tactor. In any event, we directly measured the difference in detection threshold between the finger and locations of the head. 


\subsubsection{Translation Methodology}

In figure 6, a pilot experiment determined the voltage threshold transfer function, $H_{1}=\frac{V}{S}$, which is the voltage input, $\mathrm{V}$, to the tactor which produces a sensation, $\mathrm{S}$. Measurements by Lamoré and Keemink (1988) determined the displacement threshold function, $H_{2}=\frac{D}{S}$, which is the contactor displacement, D, required to produce a sensation, $\mathrm{S}$, with or without a surround being present, as shown in figure 10. Their values were determined from tests with five participants and had a standard deviation of about $5 \mathrm{~dB}$. Note the effect of the surround to increase the touch sensitivity at frequencies below $40 \mathrm{~Hz}$. Given that the geometry of the contactor and surround is roughly the same in these two cases $\left(0.46 \mathrm{~cm}^{2}\right.$ vs. $1.5 \mathrm{~cm}^{2}$ contactor area, and $0.5 \mathrm{~N}$ vs. $0.17 \mathrm{~N}$ static force), it follows that the displacements are similar. The tactor transfer function under load is then defined as

$$
H_{3}=\frac{D}{V}=\frac{D}{S} \cdot \frac{S}{V}=H_{2} \cdot \frac{1}{H_{1}} .
$$

Assuming sinusoidal stimulation and disregarding phase shifts for each transfer, the levels of the function magnitudes in decibels are related by $L_{3}=L_{2}-L_{1}$ where the three reference quantities are explicitly stated. After the tactor function $\mathrm{H}_{3}$ has been determined, it can be used at other skin locations, with or without hair to relate threshold voltages and displacements.

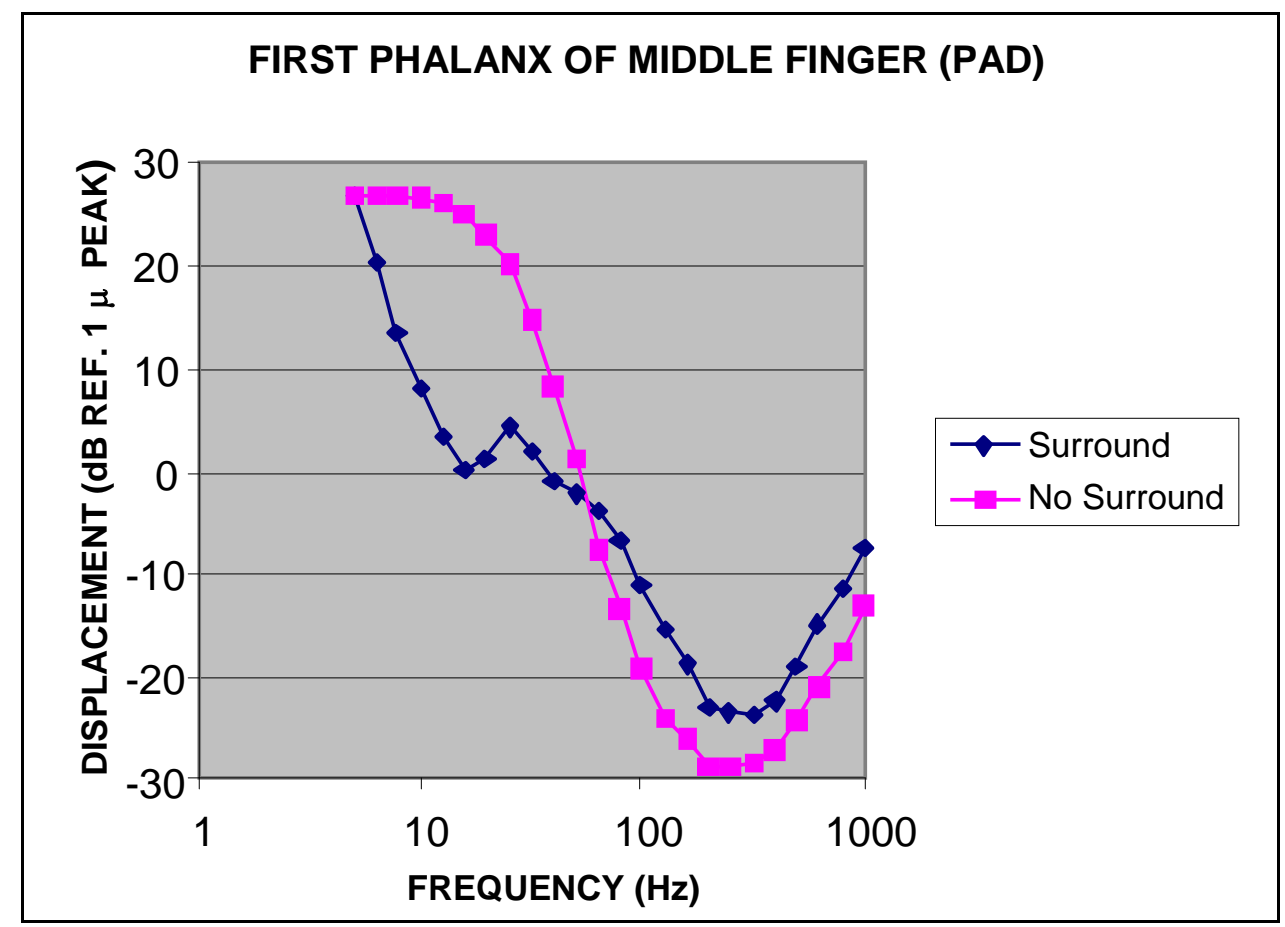

Figure 10. Vibration threshold for sinusoidal pulses for the finger with and without a rigid surround. (The curve through the data points for the five observers was fitted by eye. The standard deviation was $5 \mathrm{~dB}$. The contactor area was $1.5 \mathrm{~cm}^{2}$ and the static force was $0.5 \mathrm{~N}$ [data from Lamoré and Keemink, 1988].) 
Figure 11 shows the results of two measurements of fingertip thresholds for our four pilot participants with a reference voltage of 2.25 volts peak (the highest that could be produced free of distortion by the voltage amplifier). (Note that in general, the second trial for each participant produced more sensitive thresholds since he was improving his tracking skills and was becoming more familiar with the stimulus.) The tracking method used to determine the threshold at which detection occurs 50\% of the time is called the Best-PEST (Parametric Estimation by Sequential Testing) algorithm — a maximum likelihood method with 10 trials at each frequency (Lieberman and Pentland, 1982). This tracking method will be discussed more extensively in a later report about the psychophysical determination of tactile thresholds for the head.

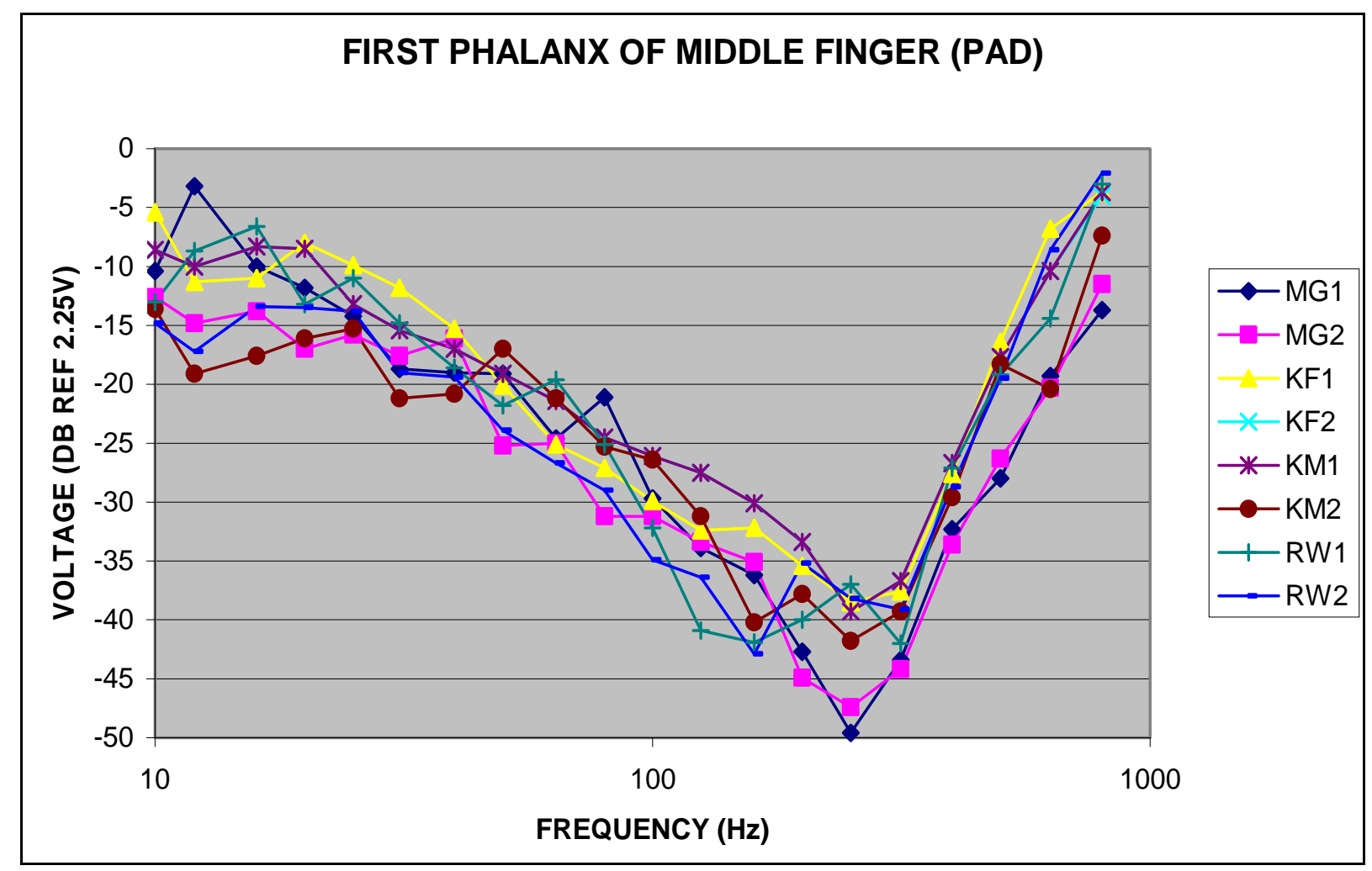

Figure 11. Tactor voltage threshold for sinusoidal pulses for the finger with a rigid surround (for four pilot participants). (The contactor area was $0.46 \mathrm{~cm}^{2}$ and the static force was $0.17 \mathrm{~N}$.)

Figure 12 shows the mean and standard deviations of the voltage thresholds for the four pilot participants. (Note that in the particular frequency range of interest [32 to $64 \mathrm{~Hz}$ ], the standard deviations were about $2.5 \mathrm{~dB}$.)

Figure 13 shows the derived electro-mechanical transfer function for the tactor, $\mathrm{H}_{3}$. Superimposed on these results are model calculations for a second order low-pass mechanical model of the tactor, based on both the mass of the contactor and loading skin along with their combined support stiffness and damping. The values chosen were indicated in Mortimer et al. (2007), which states that the resonant frequency was $250 \mathrm{~Hz}$ and the quality factor Q was low 


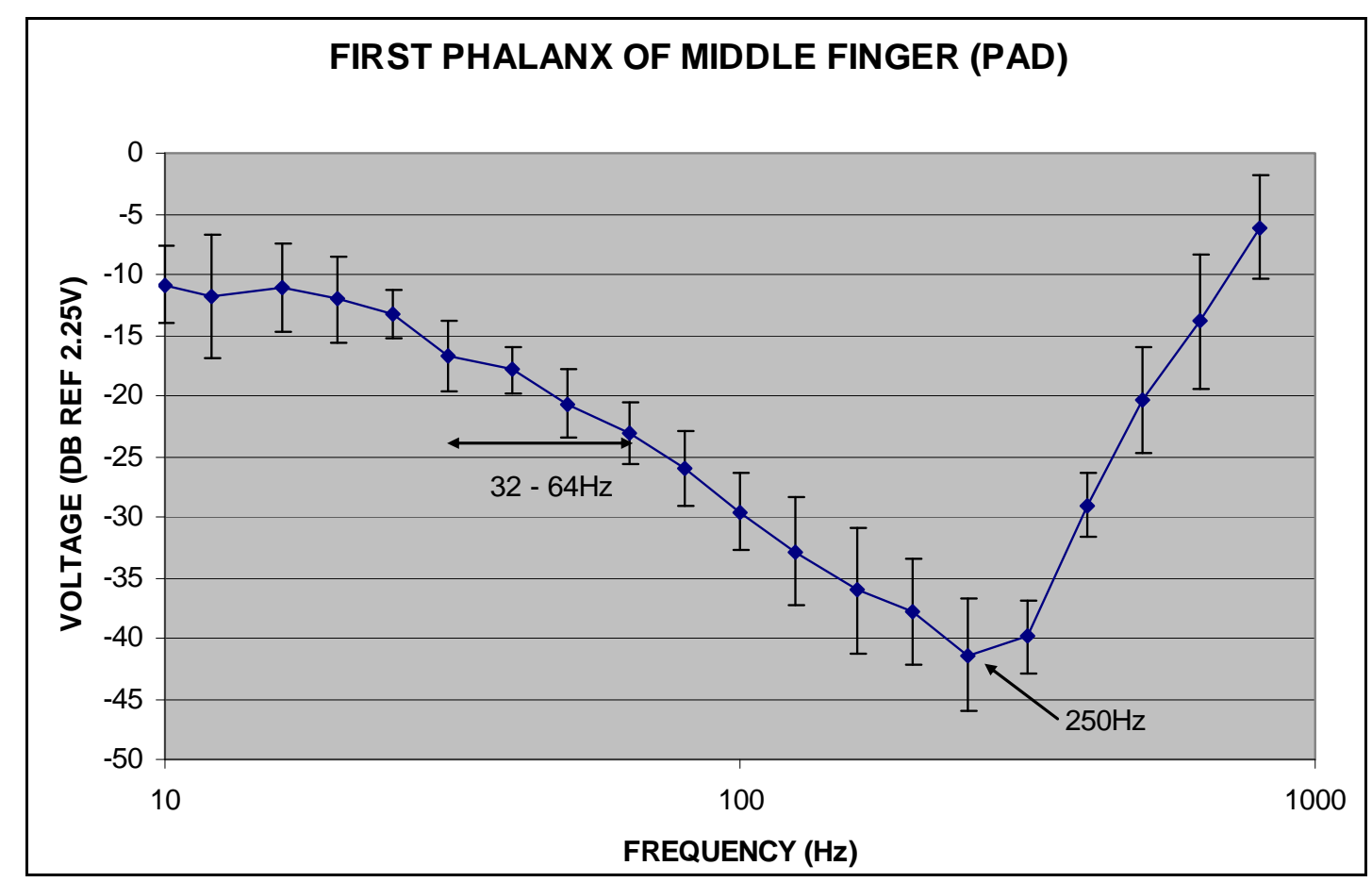

Figure 12. Tactor voltage threshold for sinusoidal pulses for the finger with a rigid surround. (The contactor area was $0.46 \mathrm{~cm}^{2}$ and the static force was $0.17 \mathrm{~N}$.)

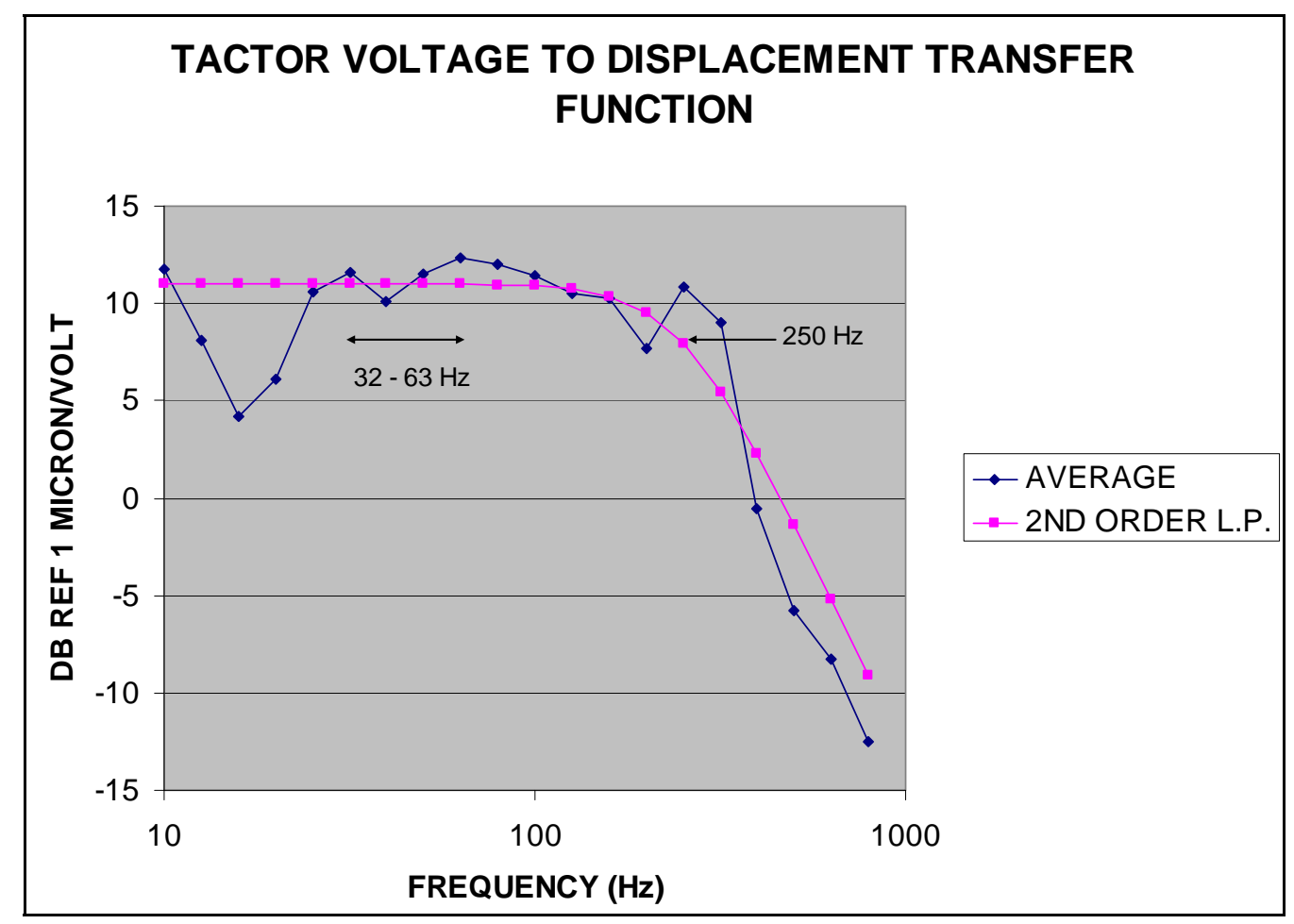

Figure 13. Tactor voltage threshold for sinusoidal pulses for the finger with a rigid surround. (The contactor area was $0.46 \mathrm{~cm}^{2}$ and the static force was $0.17 \mathrm{~N}$. Second order low-pass maximally flat Butterworth mechanical filter response with a $250-\mathrm{Hz}$ cutoff frequency, $\mathrm{Q}=0.707$ and low-frequency gain $=11.5 \mathrm{~dB}$.) 
(here chosen to be the "maximally flat response" value of 0.707 ). The low frequency gain that best fit the data was $11.5 \mathrm{~dB}$ referenced to $1 \mu \mathrm{m}$ peak per volt which is equivalent to a displacement voltage ratio of $10^{11.5 / 20}=3.76 \mu \mathrm{m}$ per volt.

It is interesting to compare this factor to the statically determined value of $40.6 \mu \mathrm{m}$ per volt (on average in figure 5 , a displacement of $30 \times 0.0001$ in was achieved for a DC current of 0.3 ampere). Assuming that the typical coil resistance was $6.25 \Omega$, this gives a displacement of $76.2 \mu \mathrm{m}$ for a drive voltage of $1.875 \mathrm{~V}$. This is about 11 times higher than our dynamically determined value. Some of this difference may be attributable to different loading conditions of the displacement gauge compared to the skin. It could also be attributable to our contactor area being three times smaller than that of Lamoré and Keemink (1988) (so that it is not true that the stimulus sensations are the same in the two cases). It is also interesting to compare these dynamic results with results from the manufacturer's data sheet giving a displacement of greater than 0.024 in for a 0.25 -ampere rms current at the resonant frequency of $250 \mathrm{~Hz}$. They also give the typical impedance as $7 \Omega$. This gives a displacement of $610 \mu \mathrm{m}$ for a peak drive voltage of $2.47 \mathrm{~V}$ or $246 \mu \mathrm{m}$ per volt. This value is 66 times higher than our value. Again, this could be attributable to differences in loading; maybe the contactor was free to move by a greater amount because it was measured free of contact with the skin. Another problem is the nature of the typical electrical impedance of the tactor. As with loudspeakers with a typical impedance of $8 \Omega$, this value is stated by the manufacturer as the minimum impedance at the loudspeaker terminals (for purposes of preventing amplifier overload) and does not represent the increasing inductive impedance with frequency. This greater impedance requires a greater voltage to produce the given amount of current. We assume that this would reduce the microns-per-volt value by a factor of 5 . This tactor model allows voltage threshold values obtained at locations on the head, for instance, to be expressed as effective displacements for comparison with other types of stimulation such as from bone conductors.

\section{Conclusions}

This memorandum report described a computer interface for driving tactile signals designed specifically for a head-mounted tactile display. Also included are a method of calibration to verify tactor output, how to generate signals for head tactile communication that avoid cross talk with the auditory modality, and the transfer functions for translating voltage thresholds to displacement thresholds. In addition, the computer interface described in this note employs commonly available parts to drive tactors for any tactile display of choice. 


\section{References}

Bergsman, P. Controlling The World With Your PC; HighText Publications: Solana Beach, CA, 1994.

Lamoŕe, P. J. J.; Keemink, C. J. Evidence for Different Types of Mechanoreceptors From Measurements of the Psychophysical Threshold for Vibrations Under Different Stimulation Conditions. Journal of the Acoustical Society of America 1988, 83 (6), 2339-2351.

Lieberman H. R.; Pentland, A. P. Microcomputer-Based Estimation of Psychophysical Thresholds: The Best PEST. Behavior Research Methods \& Instrumentation 1982, 14, 21-25.

Mortimer, B. J. P.; Zets, G. A.; Cholewiak, R. W. Vibrotactile Transduction and Transducers. Journal of the Acoustical Society of America 2007, 121 (5), 2970-2977.

Verrillo, R. T. Investigation of Some Parameters of the Cutaneous Threshold for Vibration. Journal of the Acoustical Society of America 1962, 34 (11), 1768-1773.

Verrillo, R. T. Temporal Summation in Vibrotactile Sensitivity. Journal of the Acoustical Society of America 1965, 37 (5), 843-846.

Verrillo R. T. Psychophysics of Vibrotactile Stimulation. Journal of the Acoustical Society of America 1985, 77 (11), 225-232. 
NO. OF

COPIES ORGANIZATION

\begin{tabular}{|c|c|}
\hline 1 & DEFENSE TECHNICAL \\
\hline (PDF & INFORMATION CTR \\
\hline \multirow[t]{4}{*}{ only) } & DTIC OCA \\
\hline & 8725 JOHN J KINGMAN RD \\
\hline & STE 0944 \\
\hline & FORT BELVOIR VA 22060-6218 \\
\hline \multirow[t]{7}{*}{1} & US ARMY RSRCH DEV \& \\
\hline & ENGRG CMD \\
\hline & SYSTEMS OF SYSTEMS \\
\hline & INTEGRATION \\
\hline & AMSRD SS T \\
\hline & 6000 6TH ST STE 100 \\
\hline & FORT BELVOIR VA 22060-5608 \\
\hline \multirow[t]{5}{*}{1} & DIRECTOR \\
\hline & US ARMY RESEARCH LAB \\
\hline & IMNE ALC IMS \\
\hline & 2800 POWDER MILL RD \\
\hline & ADELPHI MD 20783-1197 \\
\hline \multirow[t]{5}{*}{1} & DIRECTOR \\
\hline & US ARMY RESEARCH LAB \\
\hline & AMSRD ARL CI OK TL \\
\hline & 2800 POWDER MILL RD \\
\hline & ADELPHI MD 20783-1197 \\
\hline \multirow[t]{6}{*}{1} & DIRECTOR \\
\hline & US ARMY RESEARCH LAB \\
\hline & AMSRD ARL CI OK T \\
\hline & 2800 POWDER MILL RD \\
\hline & ADELPHI MD 20783-1197 \\
\hline & ABERDEEN PROVING GROUND \\
\hline 1 & $\begin{array}{l}\text { DIR USARL } \\
\text { AMSRD ARL CI OK TP (BLDG } 46\end{array}$ \\
\hline
\end{tabular}


NO. OF

COPIES ORGANIZATION

1 ARMY RSCH LABORATORY - HRED AMSRD ARL HR ML J MARTIN MYER CENTER RM 2D311 FT MONMOUTH NJ 07703-5601

1 ARMY RSCH LABORATORY - HRED AMSRD ARL HR MZ A DAVISON 320 MANSCEN LOOP STE 115 FT LEONARD WOOD MO 65473

1 ARMY RSCH LABORATORY - HRED AMSRD ARL HR MD T COOK BLDG 5400 RM C242 REDSTONE ARSENAL AL 35898-7290

1 COMMANDANT USAADASCH ATSA CD AMSRD ARL HR ME DR HAWLEY 5800 CARTER RD FT BLISS TX 79916-3802

1 ARMY RSCH LABORATORY - HRED AMSRD ARL HR MM DR V J RICE BLDG 4011 RM 217 1750 GREELEY RD FT SAM HOUSTON TX 78234-5002

1 ARMY RSCH LABORATORY - HRED AMSRD ARL HR MG R SPINE BLDG 333

PICATINNY ARSENAL NJ 07806-5000

1 ARL HRED ARMC FLD ELMT AMSRD ARL HR MH C BURNS BLDG 1467B RM 336 THIRD AVE FT KNOX KY 40121

1 ARMY RSCH LABORATORY - HRED AWC FIELD ELEMENT AMSRD ARL HR MJ D DURBIN BLDG 4506 (DCD) RM 107 FT RUCKER AL 36362-5000

1 ARMY RSCH LABORATORY - HRED AMSRD ARL HR MK MR J REINHART 10125 KINGMAN RD

FT BELVOIR VA 22060-5828

1 ARMY RSCH LABORATORY - HRED AMSRD ARL HR MV HQ USAOTC S MIDDLEBROOKS 91012 STATION AVE RM 348 FT HOOD TX 76544-5073
NO. OF

COPIES ORGANIZATION

1 ARMY RSCH LABORATORY - HRED AMSRD ARL HR MY M BARNES 2520 HEALY AVE STE 1172 BLDG 51005 FT HUACHUCA AZ 85613-7069

1 ARMY RSCH LABORATORY - HRED AMSRD ARL HR MP D UNGVARSKY POPE HALL BLDG 4709 BCBL 806 HARRISON DR FT LEAVENWORTH KS 66027-2302

1 ARMY RSCH LABORATORY - HRED AMSRD ARL HR MJF J HANSBERGER JFCOM JOINT EXPERIMENTATION J9 JOINT FUTURES LAB 115 LAKEVIEW PKWY STE B SUFFOLK VA 23435

1 ARMY RSCH LABORATORY - HRED AMSRD ARL HR MQ M R FLETCHER US ARMY SBCCOM NATICK SOLDIER CTR AMSRD NSC WS E BLDG 3 RM 343 NATICK MA 01760-5020

1 ARMY RSCH LABORATORY-HRED AMSRD ARL HR MT J CHEN 12423 RESEARCH PKWY ORLANDO FL 32826

1 ARMY RSCH LABORATORY - HRED AMSRD ARL HR MT C KORTENHAUS 12350 RESEARCH PKWY ORLANDO FL 32826

1 ARMY RSCH LABORATORY - HRED AMSRD ARL HR MS C MANASCO SIGNAL TOWERS BLDG 29808A RM 303 FT GORDON GA 30905-5233

1 ARMY RSCH LABORATORY - HRED AMSRD ARL HR MU M SINGAPORE 6501 E 11 MILE RD MS 284 BLDG 200A 2ND FL RM 2104 WARREN MI 48397-5000

1 ARMY RSCH LABORATORY - HRED AMSRD ARL HR MF C HERNANDEZ 2421 NW AUSTIN RD STE 220

FT SILL OK 73503-9042 
NO. OF

COPIES ORGANIZATION

1 ARMY RSCH LABORATORY - HRED

AMSRD ARL HR MW E REDDEN

BLDG 4 ROOM 332

FT BENNING GA 31905-5400

1 ARMY RSCH LABORATORY - HRED

AMSRD ARL HR MN R SPENCER

DCSFDI HF

HQ USASOC BLDG E2929

FT BRAGG NC 28310-5000

1 ARMY G1

(CD DAPE MR B KNAPP

only) 300 ARMY PENTAGON ROOM 2C489

WASHINGTON DC 20310-0300

ABERDEEN PROVING GROUND

2 DIR USARL

AMSRD ARL CI OK TP

S FOPPIANO

AMSRD ARL HR MR

F PARAGALLO 